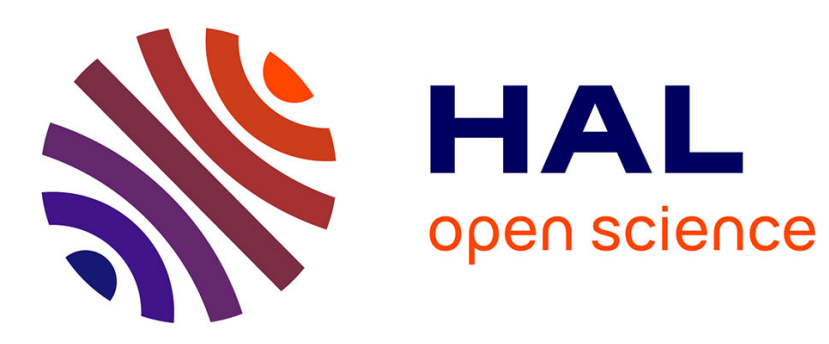

\title{
Efficient numerical method for evaluation of sound field in room
}

\author{
M. Milosevic, B. Milovanovic, B. Radlovic
}

\section{To cite this version:}

M. Milosevic, B. Milovanovic, B. Radlovic. Efficient numerical method for evaluation of sound field in room. Journal de Physique IV Proceedings, 1994, 04 (C5), pp.C5-143-C5-146. 10.1051/jp4:1994525 . jpa-00252938

\section{HAL Id: jpa-00252938 https://hal.science/jpa-00252938}

Submitted on 1 Jan 1994

HAL is a multi-disciplinary open access archive for the deposit and dissemination of scientific research documents, whether they are published or not. The documents may come from teaching and research institutions in France or abroad, or from public or private research centers.
L'archive ouverte pluridisciplinaire HAL, est destinée au dépôt et à la diffusion de documents scientifiques de niveau recherche, publiés ou non, émanant des établissements d'enseignement et de recherche français ou étrangers, des laboratoires publics ou privés. 


\title{
Efficient numerical method for evaluation of sound field in room
}

\author{
M.A. MILOŠEVIĆ, B.D. MLLOVANOVIĆ and B.D. RADLOVIĆ \\ Faculty of Electronic Engineering, Beogradska 14, 18000 Niš, Serbia, Yugoslavia
}

\begin{abstract}
Among frequently used approaches for evaluation of the sound field inside a room is the one based on using of image source method. This method has the advantage of a very accurate calculation of the reflections, but for higher order reflections, the calculation explodes due to an exponential increase of the number of possible image sources. Numerical method which makes the convergence of the infinite row in the sound level computation faster, will be presented in this paper. In this way the sound level at an arbitrary room point can be predicted only by means of the energy contribution of a relatively small number of image sources considerably shortening the computing time.
\end{abstract}

\section{INTRODUCTION}

The theoretical evaluation of the sound field distribution inside a room is possible today thanks to modern calculation by acoustic computer models. These models are based on classical geometrical methods. One of frequently used approaches for evaluation of the sound field inside a room is based on the well-known image source method. This method has the advantage of a very accurate calculation of the reflections, but for higher order reflections, the calculation explodes due to an exponential increase of the number of possible image sources.

Numerical method which makes faster the convergence of the infinite row in the sound level computation using the image source method, is presented in this paper. In this way the sound level at an arbitrary point can be predicted only by means of the energy contribution of a relatively small number of image sources and the computing time is therefore significantly shorter.

The sound levels of a given point in the room have been measured and compared with results computed using the image source method and proposed numerical method. The analyses of the measured values and calculated results in the real room, as well as analyses of requested number of image sources using the image source method and proposed method, establish unambiguously the advantage of the proposed approach.

\section{IMAGE SOURCE METHOD}

By use of the image source method, the acoustic energy density in both, sound-diffused and incompletelysound-diffused rectangular room, can be evaluated by summing up the energy density of the direct sound wave from a real source with acoustic power $P$ and the energy density of sound waves from all of the image sources lower than the $n$-th reflection wave against the boundary surfaces. Let $N_{j}(j=1,2 \ldots, n)$ be the number of image sound sources $\left(\mathrm{N}_{0}=1\right.$ for direct sound wave) for only the $\mathrm{j}$-th reflections against each wall and ceiling whose the mean absorption coefficient is $\vec{\alpha}$, and the reflections against the floor whose sound absorption coefficient $\left(\alpha_{\mathrm{f}}\right)$ may be changed. If the absorption in the air is neglected, the formula for 
the sound energy density at the given point in a rectangular room is

$$
W_{n}=\frac{P}{4 \pi c} \sum_{j=0}^{n} \sum_{i=0}^{N_{j}} \frac{\left(1-\alpha_{f}\right)^{n_{f j i}}(1-\bar{\alpha})^{j-n_{f j i}}}{r_{j i}^{2}}
$$

where $\mathrm{n}$ is the number of reflection from the floor of the $\mathrm{i}$-th image source by the $\mathrm{j}$-th reflection against each wall, $\mathrm{r}$ is the distance between the corresponding image sound source and the receiving point and $\mathrm{c}$ is the sound speed in the air.

\section{IMPROVED METHOD}

To accelerate the convergence of the series given by Eq.(1), a numerical Aitken $\Delta^{2}$ transform [5]

$$
W_{n}^{m+1}=W_{n+2}^{m}-\frac{\left(W_{n+2}^{m}-W_{n+1}^{m}\right)^{2}}{\left(W_{n+2}^{m}-2 W_{n+1}^{m}+W_{n}^{m}\right)}, \quad n=0,1,2, \ldots
$$

is applied, where $W_{n}$ is a sequence of partial sums, and $m$ is the order of Aitken's transform. Obtained sequence $W_{n}^{1}(\mathrm{n}=0,1,2, \ldots)$ convergates faster than the original sequence $W_{n}^{0}(\mathrm{n}=0,1,2, \ldots)$. The convergence criterion is here given by

$$
\left|\frac{W_{n}^{m}-W_{n-1}^{m}}{W_{n-1}^{m}}\right| \leq \Delta
$$

where $\Delta$ is the required accuracy. The convergence criterion is said to be met if three successive values of n satisfy the criterion.

\section{CALCULATION RESULTS AND EXPERIMENTAL CONSIDERATIONS}

For the purpose of a comparison with the computed results, the sound pressure level has been measured in the rectangular room. The dimensions of the room are $(6,2 \times 8,9 \times 3,8) \mathrm{m}^{3}$. The sound source type 4224 $\mathrm{B} \& \mathrm{~K}$ was located just in front of the lower corner. The microphone type $4165 \mathrm{~B} \& \mathrm{~K}$ was located near the mid-point of the room. The sound pressure levels have been measured using the real-time frequency analyzer type $2143 \mathrm{~B} \& \mathrm{~K}$. The concrete floor was covered with the specimen, so chosen that its absorption coefficient changed from 0,18 to 0,9 over the range of frequencies $(125 \div 1000) \mathrm{Hz}$ used in this experiment.

The numerical evaluation of Eq.(1), for the case of 0,9 floor absorption coefficient (covered with the specimen) and 0,04 mean absorption coefficient of the other walls, is given in Fig.1. (solid line) as a function of the number of reflection $n$. For a convergence criterion $\Delta=10^{-4}$, the classical image source method achieves steady state for $n=89$, while the result after applying the first-order $(m=1)$ and secondorder $(m=2)$ Aitken's transform is obtained for $n=49$ and $n=23$, respectively. The necessary number of image sources is decreased from 956038 to only 4161798 and 17342, respectively. In this case Aitken's transform (taken by second-order acceleration) diminishes the computation time into one 65th the time of the classical image source method. 


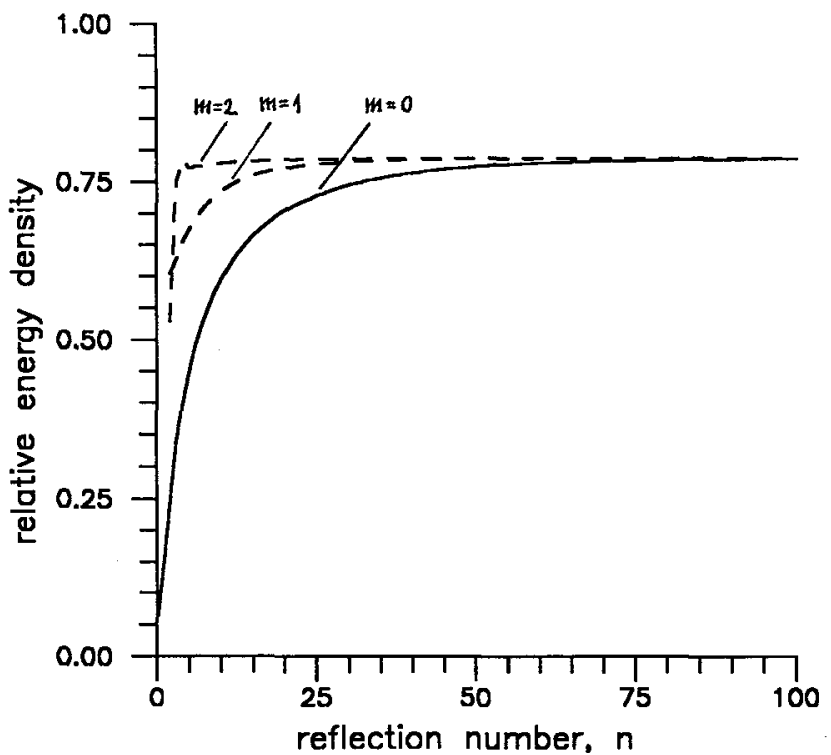

Fig. 1. Relative sound energy density estimated by ISM $(\longrightarrow)$ and improved ISM (----) as a function of the reflection number

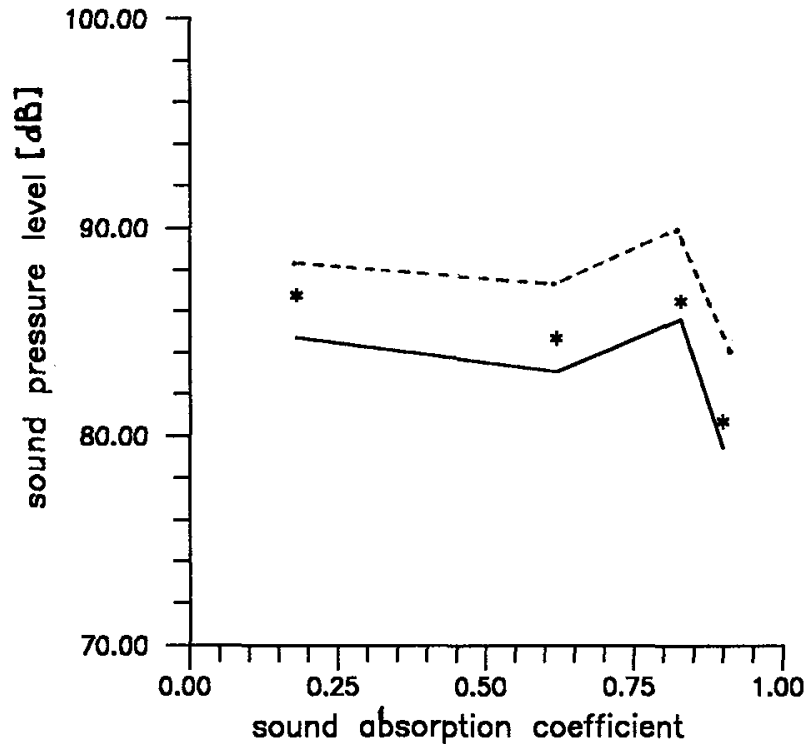

Fig.2. A comparison between the theoretically estimated values and the experimentally sampled points for the sound pressure levels at receiving point. (*) experimental values; (-) proposed method; (----) Eq.(4) 
Fig.2. shows the sound pressure levels at measurement point, in spatial comparison with those evaluated by proposed method and by use of the following expression:

$$
L=10 \log \left[\frac{P}{4 \pi r^{2}}+\frac{4 P}{S \alpha}(1-\alpha)\right]+120
$$

where $S$ is the total surface area, and $\alpha$ is the mean absorption coefficient of all walls in the room. Note that the agreement between the experimental results and the theoretically estimated values is better in the case of application of the improved image source method. This is due to the fact that Eq.(4) is good only for the room with uniform distribution of sound. In case when there is absorbing material placed only at the floor of the room, the sound field is surely in an undiffused situation, and therefore more accurate formula should be used [for example, Eq.(1)]. Since Aiken's transform eliminates the labour and time of the complicated calculation procedures based on many of the higher order image sources, the sound pressure levels can be estimated (using the image source method) easily and more precisely.

\section{CONCLUSIONS AND FURTHER ASPECTS AND DEVELOPMENTS}

The application of Aitken's transform substantially improves the convergence of the infinite series for the sound energy density. Using this approach, the sound field in the room can be predicted in relatively short computation time. Additionally, it allows us determination of the changes in sound field throughout the room due to additional sound sources, as well as dependence of their position and position of absorption material. In general, this approach enables a fast sound field anticipation and can be used successfully in designing many variational room models. The valadity and effectiveness of the proposed method has been experimentally confirmed by applying it to an actual rectangular room, as well.

\section{REFERENCES}

[1] Milošević M., "Evaluation of the Sound Absorption Coefficient in Rectangular Room", XIX Yugoslav Conf., ETAN, Ohrid 1975, pp.735-743 (in Serbian).

[2] Janeček P., Acustica 74 (1991), 149-156.

[3] Ohta M., Iwashige K. and Nakamura K., Acustica 77 (1992), 12-20.

[4] Dammig P., Acustica 75 (1991), 105-120.

[5] Milovanović B., "Numerical Analyses of the Coupled Microstrip Lines", XXVIII Yugoslav Conf., ETAN, Subotica, 1982, pp.II.651-II.658 (in Serbian).

[6] Milošević M., Milovanović B. and Radlović B., "Effective Numerical Determination of a Sound Level in the Rectangular Room", XIV Yugoslav/ II International Conf., "Noise and Vibration", Niš, 1993, pp.143-150 (in Serbian). 